\title{
Gunshot Injury in Neck; Suicide or Homicide?
}

\author{
Anil Garg ${ }^{1}$, Shakshi Sharma ${ }^{2}$, Yogendra Malik ${ }^{3}$, Yogesh Kumar Vashist ${ }^{4}$, Pawan Mittal ${ }^{5}$, Gaurav Sharma ${ }^{6}$, \\ Bhavya Kalra ${ }^{7}$ \\ ${ }^{1}$ Professor, Deptt. of Forensic Medicine, BPS Govt Medical College for Women, Khanpurkalan, Gohana, Sonipat, \\ ${ }^{2}$ Scientific Assistant (Ballistics Divison) Forensic Science Laboratory (Haryana), Madhuban, Karnal, ${ }^{3}$ Professor, \\ ${ }^{4}$ Assistant Professor, ${ }^{5}$ Demonstrator, ${ }^{6}$ Professor \& Head, ${ }^{7}$ Ex-resident, Deptt. of Forensic Medicine, BPS Govt \\ Medical College for Women, Khanpurkalan, Gohana, Sonipat
}

\begin{abstract}
Forensic investigation of a gunshot related death can be a challenging process. When ascertaining the manner of death, the forensic expert should be careful, as, attempts are not uncommon to disguise homicides as suicides. Abnormal and unusual location of gunshot wound adds to this suspicion. The case under discussion highlights the role of a forensic expert in the ascertainment of the manner in firearm deaths. The deceased was a criminal who was absconding and when his where about were revealed to the investigating agency, he was followed to arrest but, upon reaching the spot in the sugarcane fields, there was exchange of fire and his dead body was found with the weapon lying near him. A thorough complete autopsy and detection of gun powder residue on hands lead to the unfolding of this mystery.
\end{abstract}

Key words: Firearm, Suicide, Gunpowder residue, Autopsy

\section{Introduction}

One of the most important tasks in forensic medicine is differentiating between a homicide and a suicide, but fabrication of circumstances of fatal events is very common and cases are often misled. Manner of deaths due to firearms can be accidental, suicidal or homicidal. Accidental firearms deaths are rare and are usually due to careless handling of the weapon ${ }^{1}$. In suicidal deaths due to firearms, the identification of the shooter, medico-legal assessment of all the facts during the autopsy and the investigation results are essential. Therefore, complete postmortem examination including sufficient history, crime scene visit, meticulous autopsy, and ancillary investigations should be performed which

\section{Corresponding author:}

\section{Dr.Yogesh Kumar Vashist,}

Assistant Professor, Deptt. Of Forensic Medicine, BPS Govt Medical College for Women, Khanpurkalan, Gohana, Sonipat also include gunshot residues for the identification of the shooter ${ }^{2}$.

\section{Case Report}

Received dead body of a male individual of length $165 \mathrm{~cm}$ wrapped in a white sheet of cloth. It was wearing a khakki coloured front zip open full sleeved jacket which was smudged with blood and mud at places, with black powder in the coloured area a gray coloured half sleeved $t$ shirt with front design obliquely placed a white coloured sandooz baniyan a blue black coloured jeans with brown colour belt in loops around waist with zip and button closed, a pair of gray coloured shoes with laces tied around the ankle, a pair of black coloured socks in each foot a gray coloured underwear with elastic waist line around waist with Lux Cozi written at waist area and red colour sacred thread around neck with a metallic locket. Rigor Mortis present all over the body. Post mortem staining was present on back except areas of contact flattening. Dried blood stains were present on the right side of neck with black colour tattooing in right 
lower half of neck and the right angle of mandible (Figure 1). Pupils were dilated, Cornea/Conjunctiva were hazy, mouth was partially open.

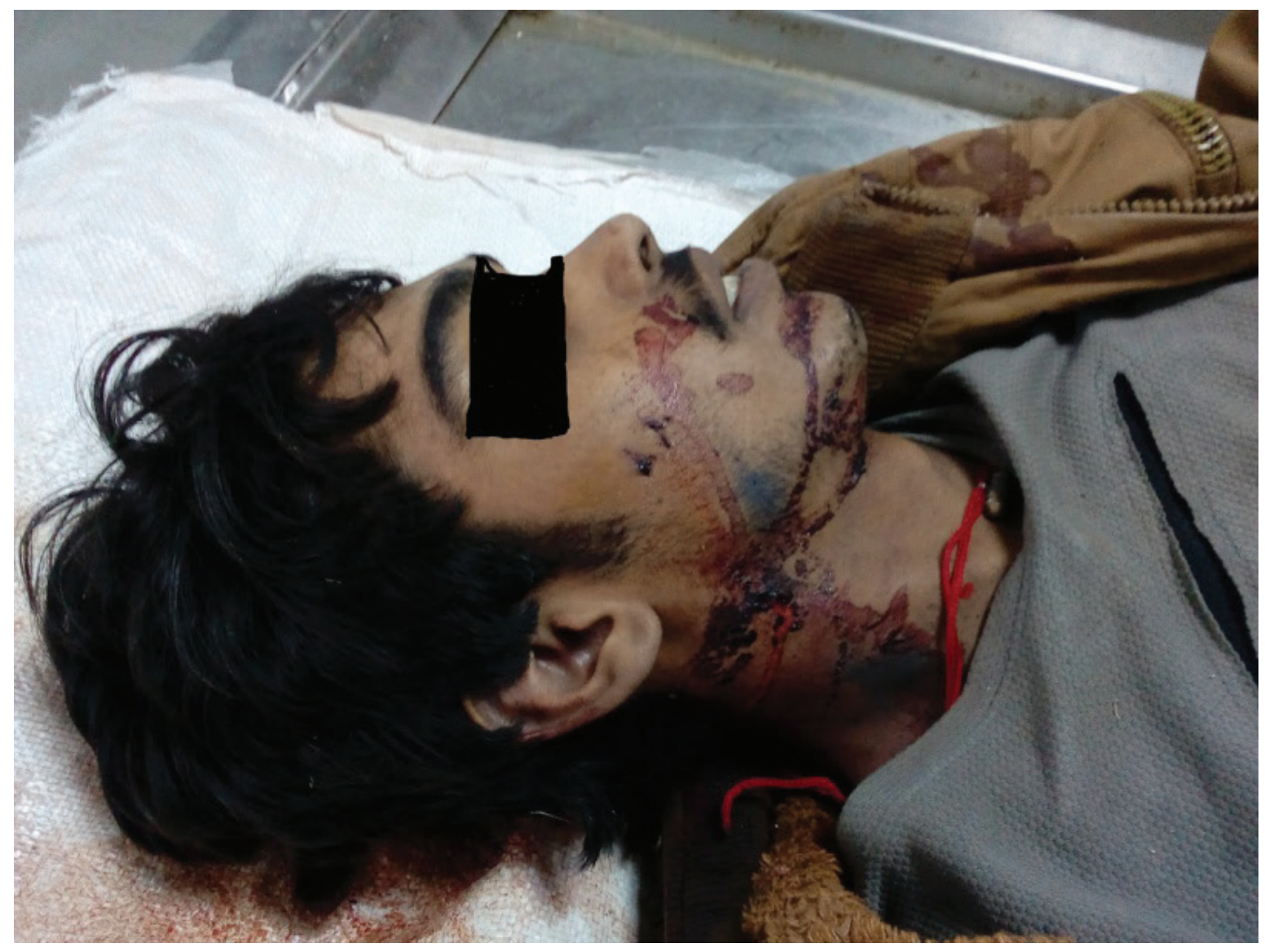

Figure 1: showing blood stains and tattooing

Injuries: An entry wound of firearm, of size $0.8 \mathrm{~cm}$ $\mathrm{x} 0.6 \mathrm{~cm}$, oval in shape with abrasion collor all around located in the right upper region of neck situated $144 \mathrm{~cm}$ above the right heal, $10 \mathrm{~cm}$ from center of chin, $5 \mathrm{~cm}$ below the right mandible, $2 \mathrm{~cm}$ below and lateral to the right angle of mandible, (Figure 2) with liquid blood oozing out. The wound was directed upwards, backwards, from right to left, which was lacerating the right side of neck muscles, with fracture of the base of the skull of right half, further going upwards tearing the dura mater, the right half of the cerebral hemisphere, crossing the midline in the upper temporal region on to the left cerebral hemisphere, $2 \mathrm{~cm}$ from midline where a deformed grayish silvery metallic bullet (Figure 3) of size $1.2 \mathrm{~cm} \times 0.8 \mathrm{~cm}$ with irregular shape, was lodged surrounded with clotted blood. (Figure 4) All along the track, red colour liquid and clotted blood was present in track. The tissues around the track were torn irregularly, brain was lacerated and torn.

Cause of Death is firearm injury as described and its complication. The probable time that elapsed between death $\&$ autopsy was opined to be 12 to 24 hours.

The recovered bullet, bilateral hands swab, swab from the neck region, along with $x$ ray film, $C D$ of videography done during post mortem examination was preserved and handed over to the accompanying police person. 


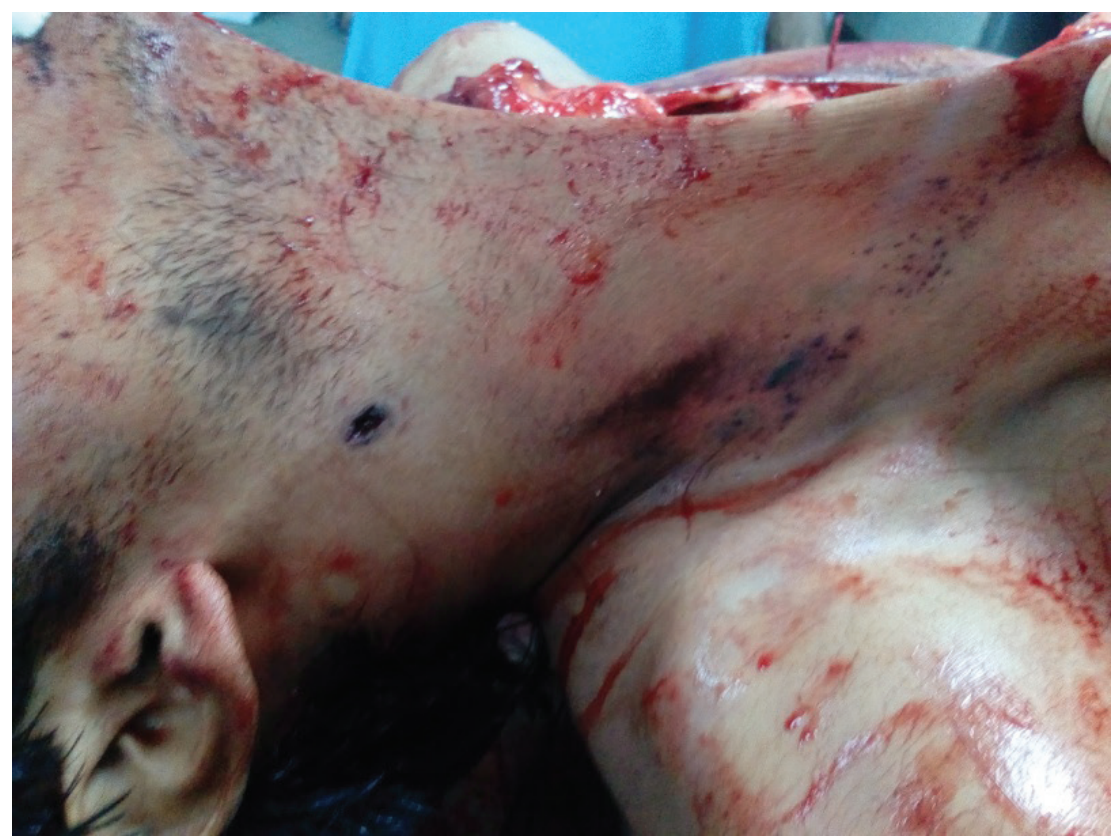

Figure 2: showing entry wound of firearm

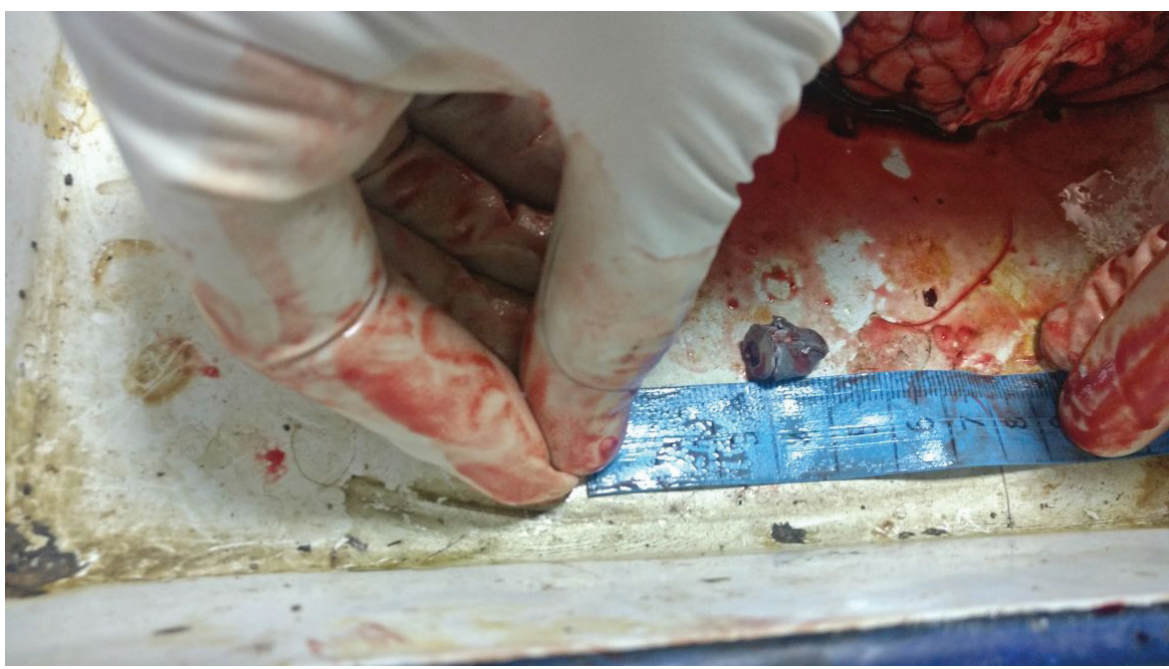

Figure 3: showing metallic bullet

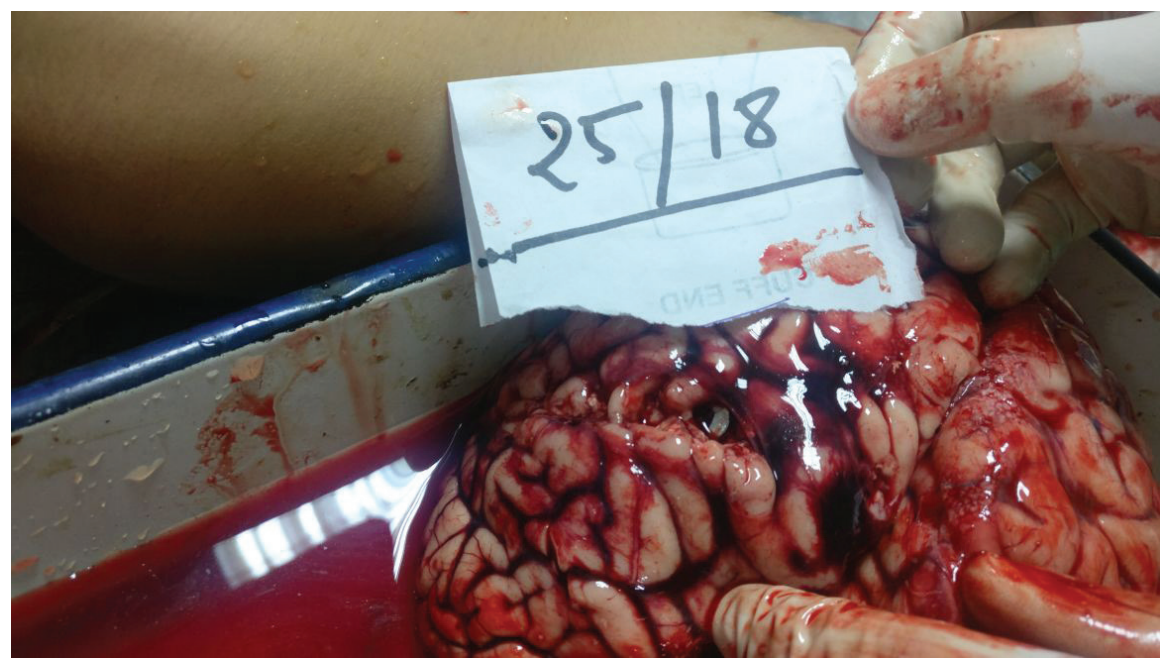

Figure 3: showing surrounding hemorrhage in brain. 
The Forensic Science laboratory confirmed that the bullet was fired from the gun found in the vicinity of the deceased at the crime scene. The forensic investigations also confirmed the presence of gunpowder from the deceased's hand, thus confirming it to be a case of suicide. Gunpowder residue was also detected on the jacket on its collar area (Figure 5).

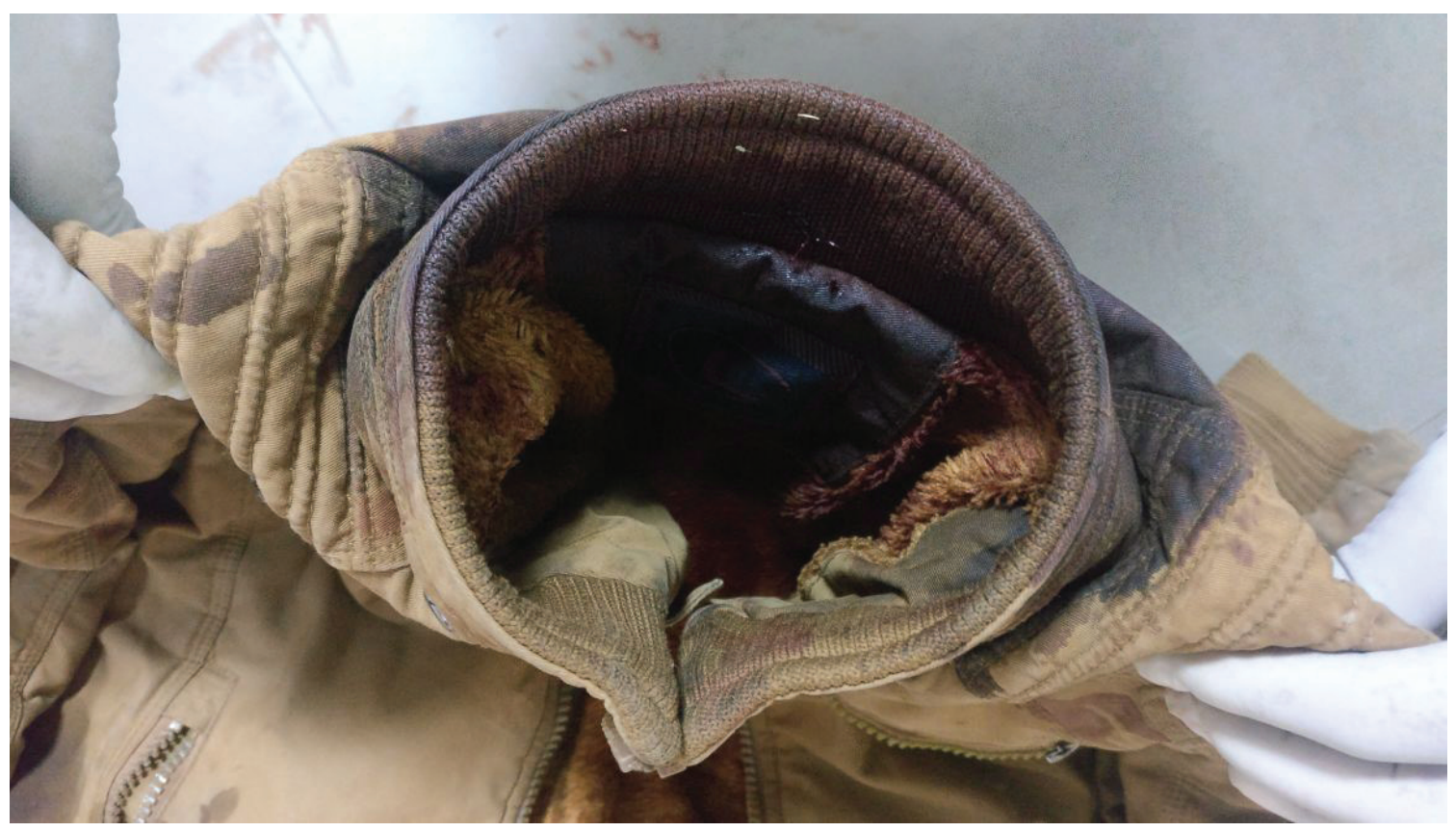

Figure 5: Showing color of Jacket

\section{Discussion}

In a firearm-related injury, the direction that a bullet travels through a body may have little relevance in a patient's clinical management, but it usually has profound medico-legal implications. Entrance and exit wounds, bullet projectile pathway, range of gunshot and manner of inflictions are some of important information usually gathered from the autopsy ${ }^{3}$. In deaths due to firearm, detection and identification gunshot residue (GSR) from fire arm discharge may provide valuable investigative information, whether there is a primary association of a person or surface with the discharge of a weapon or subsequent handling of a discharged weapon ${ }^{4}$. These residues are principally composed of burnt and un burnt particles from the propulsive charge, as well as components from the primer, the bullet, the cartridge case and the firearm itself, and they are generally called gunshot residue ${ }^{5}$ (GSR) and gets deposited on the firing hand ${ }^{6}$.
Suicide is one of the leading causes of death in multiple age groups, and among firearms handguns is the most common weapon of choice, with some variation ${ }^{7}$. The firearm is usually held close to and often in contact with the body in suicide ${ }^{8}$. In handgun suicides, gunshot wounds are usually located to the head $(81 \%)$ and the chest (17\%), with other regions namely the mouth, left temple, and submental regions ${ }^{9}$. However in this case, the site was on the right side of neck just below the right sub mental triangle, which reveals it to be an un common site, with faintly visible muzzle impression, as the skin in the neck region is lax and elastic, which tends to yield on pressure with splattering of gases and the gunpowder residue in the surrounding skin, as could be appreciated from the images (Figure 5) Shoot pattern over the wound suggested the near contact range fire. Presence of gunshot residue (GSR) over the hands of the deceased indicated that the deceased made fire. Thus, an unusual location of wound does not necessarily mean that it cannot be self-inflicted, though it is wise to always 
start with the assumption that such a case is a homicide.

\section{Conclusion}

Unusual sites of firearm wounds should be carefully examined and all the ancillary investigations to be done, before giving the final opinion .Autopsy, ballistic, forensic chemistry and lab findings were evaluated in order to conclude as a case of suicide.

\section{Conflict of Interest - None}

\section{Source of Funding- Self}

Ethical Clearance - It is medicolegal case report thus does not required.

\section{References}

1. Werner US, Daniel JS. Spits and Fisher's Medicolegal investigation of death, [1] $4_{\text {th }}$ ed. Springfield: Charles C Thomas; 2006. Injury by gunfire. In: Spitz WU; Pp. 607-746.)

2. Padosch SA, Schmidt PH, Schyma C, Hirsch RD, Kröner LU, Dettmeyer RB, et al. Medicolegal aspects of witnessed suicide due to gunshot to the head. II. Legal medicine aspects and examination of the firing hand. Arch Kriminol. 2004;214(56):149-62.)

3. Beasant Matthews PE. 2000. Examination and interpretation of riffled firearm injuries. In: The Pathology of Trauma. Mason JK, Purdue BN. 3rd ed. London: Edward Arnold. Pp 47-60

4. Clark SC (1999) Death Investigation: A Guide for the Scene Investigator. National Institute of Justice, Washington, USA)

5. Francesco SR, Pierre M (2001) Identification of gunshot residue: a critical review. Forensic Science International 119(2): 195-211.

6. Dodd MJ. Terminal Ballistics -A Text and Atlas of Gunshot Wounds. USA; CRC Taylor \& Francis 2006. p. 137

7. Zwerling C, Lynch CF, Burmeister LF, Goertz U. The choice of weapons in firearm suicides in Iowa. Am J Public Health 1993;83(11):1630-1632

8. Stone IC. Characteristics of firearms and gunshot wounds as markers of suicide. Am J Forensic Med Pathol 1992;13(4):275-280

9. Di Maio VJM. Gunshot wounds,) practical aspects of firearms, ballistics, and forensic techniques. 3rd ed. Boca Raton, FL: CRC Press, 2016. 